\title{
La imprenta y el periodismo en las regiones de México (1539-1820)
}

\section{Celia del Palacio Montiel** celiap@csh.udg.mx}

\begin{abstract}
$\mathrm{El}$ presente trabajo pretende presentar una visión comparativa de cinco regiones de México, tras la llegada de la imprenta y los inicios del periodismo en Oaxaca (Antigua Antequera), Veracruz (Provincia de Veracruz), Jalisco (Nueva Galicia), Yucatán (Provincia de Yucatán) y Michoacán (Valladolid) entre los siglos XVI y XIX, largo periodo de transición que comprende la mayor parte de la época colonial, hasta la consumación de la Independencia.
\end{abstract}

This article presents a comparative approach of five Mexican regions taking as a tool of analysis the arrival of the printing press and the beginnings of the journalistic activity in Oaxaca, Veracruz, Jalisco, Yucatán and Michoacán, in the $16^{\text {th }}$ to the $19^{\text {th }}$ centuries, long transition age that takes into account most of the colonial years until the consummation of the independence movements.

Los historiadores no avezados en los estudios coloniales podrían considerar los tres siglos de dominación española en México como una época de inmovilidad y oscurantismo cultural, en contraste con el siglo XIX, cuando las pasiones independentistas y las discusiones políticas y religiosas tienen lugar, sin embargo resulta vital considerar el largo periodo de desarrollo tanto tecnológico como ideológico anterior a la emancipación, a fin de poder explicar el advenimiento de las nuevas ideas y de las nuevas doctrinas políticas y sociales, así como el nacimiento de la esfera pública en vísperas de la Independencia de la Nueva España.

Un elemento de capital importancia que hay que considerar para comprender el nacimiento de la esfera pública, es el estable-

*Universidad de Guadalajara. 
cimiento de la imprenta y el nacimiento del periodismo (Habermas 1991; Guerra 1992). Ésa, en México, es una larga historia que comienza en 1539, sin embargo, no es una historia única y lineal: se fragmenta en tiempo y espacio. Aún ahora México es un país lleno de contrastes, diferente en sus costumbres según sus regiones. Durante la colonia y los primeros años del siglo XIX esta fragmentación y estas diferencias eran aún más grandes. No se debe contar la historia sólo desde el centro, a riesgo de que resulte un tanto miope y limitada.

Este artículo pretende dar cuenta de algunos de los desfases en el establecimiento de la herramienta tecnológica: la imprenta; y del vehículo de las ideas: el periódico, en cinco lugares lejanos de la capital.

\section{BREVÍSIMO RECUENTO HISTÓRICO DE LAS HISTORIAS DE LA PRENSA}

La historia de los impresos, particularmente de los periódicos en México es larga. Se inició a fines del siglo XIX, con los trabajos de concienzudos bibliófilos como José Toribio Medina o Juan B. Iguíniz, quienes tomaron a su cargo la dura tarea de recopilación de los materiales dados a la luz por las diferentes imprentas mexicanas. Herederos de los eruditos bibliógrafos de los siglos anteriores, como Eguiara y Eguren o Beristain, los acuciosos intelectuales mencionados dieron inicio al estudio moderno de los impresos en México.

Medina realizó monumentales estudios sobre algunas de las regiones de México como Oaxaca, Guadalajara, Puebla de los Ángeles, Veracruz y Mérida. Iguíniz, aunque escribió sobre diversos temas relacionados con los impresos, se especializó en la historia de la prensa y el periodismo de Guadalajara.

El estudio de los periodismos regionales continuó a lo largo del siglo xx, a cargo de historiadores locales, memoriosos que dieron a la estampa sabrosas anécdotas sobre lo publicado en diferentes lugares del país. Sin embargo, ya en las últimas décadas de ese siglo comenzaron a producirse historias del periodismo 
mexicano en toda forma. Lamentablemente, esas historias fueron dejando en la sombra cada vez más a las regiones de México. El centralismo produjo historias del periodismo mexicano que se limitaron a hablar del periodismo en la ciudad de México.

En los años más recientes, una nueva generación de historiadores y estudiosos de la comunicación han buscado nuevos enfoques para volver (y muchas veces incursionar por primera vez) al estudio de la prensa en las regiones de México.

Inspirados por los estudiosos de la historia cultural, abordando los paradigmas de investigación sobre la cultura impresa en sus diferentes manifestaciones, estos jóvenes investigadores han agregado nuevos temas y nuevas interrogantes al estudio de la producción, circulación y consumo de bienes culturales en las provincias de México.

En esa línea de investigación se inscribe el presente artículo, que es una primera aproximación a un estudio comparativo de la prensa y el periodismo en cinco regiones de México. ${ }^{1}$

Después de realizar estudios en torno a los inicios de la prensa en diversos lugares del país, estoy convencida de que mucho depende del carácter regional y otras determinaciones que tienen que ver con el desarrollo material y cultural de las diversas regiones el cómo y cuándo se inicie con la tarea de imprimir libros y producir periódicos.

En el presente trabajo me daré a la tarea de resumir cómo fueron los inicios de la prensa en cinco diferentes regiones de México: aquéllas comprendidas en su mayor parte por los estados de Jalisco, Michoacán, Oaxaca, Veracruz y Yucatán, para luego llegar a algunas conclusiones a partir de la comparación de los procesos.

Antes que nada, resulta imperativo definir el concepto principal que se aborda aquí: región. Aunque en el párrafo anterior perecería que se usarán región y estado como sinónimos, no es el caso. Resulta sin embargo difícil establecer qué concepto se usa-

${ }^{1}$ Este estudio forma parte del proyecto Historia comparativa de la prensa regional en México, 1792-1950, el cual ha sido apoyado por el Conacyt. 
rá, ya que las regiones a que me refiero aquí no corresponden siempre a los "estados": denominaciones territoriales basadas en criterios jurídicos y políticos, históricamente determinados, que hoy conocemos.

No quiero aquí, sin embargo, abundar demasiado en la definición de región, que ha ocupado a diversos historiadores y teóricos. ${ }^{2}$ Si nos ceñimos a la definición más elemental, región es la división que se hace de un territorio para su estudio, tomando en cuenta sus características o elementos que la identifiquen como tal. Así, dentro de México como país existen diversas regiones culturales, geográficas, gastronómicas, que no siempre coinciden con las denominaciones territoriales jurídicamente configuradas. En el caso del presente artículo, adoptaré esta definición elemental y procuraré probar que, en efecto, existen algunas características regionales que diferencian a un lugar de otro y que estas características dan un carácter distintivo a cada una de las regiones estudiadas y las maneras que tuvo cada una de ellas de establecer primero y utilizar después la tecnología (es decir la imprenta) para producir impresos y posteriormente periódicos (el producto cultural propiamente dicho).

Se ha preferido el enfoque comparativo, ya que creemos que éste puede proporcionar al estudioso de la historia elementos que permitan encontrar qué hay de específico, de único, en un fenómeno, en una región y dónde pueden encontrarse regularidades y patrones (Burke 1997: 34). Así, podría llegarse a conclusiones más certeras respecto a la historia de la prensa y del periodismo en México, ya que hasta hace muy poco tiempo estas historias pretendían homogenizar todo el territorio del país e igualarlo con lo sucedido en la ciudad de México.

${ }^{2}$ Para el caso de México, resulta útil consultar la recopilación que hizo Pedro Pérez Herrero, a manera de "manual" para el estudio de la región, donde incluye artículos de los autores más representativos en la corriente de la historia regional: Luis González y González, Carol Smith, Eric Van Young, Guillermo de la Peña, P. E. Ogden, Robert Sack y Marcello Carmagnani, para diferentes factores que determinan la regionalidad: los demográficos, económicos y políticos, entre otros. 


\section{CinCo MANERAS DE EMPEZAR A CONTAR ¿Por qué esos lugares?}

Se decidió analizar a estas cinco regiones porque fueron las primeras en contar con una imprenta, después de la ciudad de México y Puebla. ${ }^{3}$ Asimismo, fueron estos lugares los primeros en producir periódicos fuera de la capital. También se ha visto que los procesos culturales de estos lugares son lo suficientemente disímiles como para establecer comparaciones que puedan resultar interesantes; además, son lugares que guardan una gran distancia geográfica y pueden ser representativos de las diferentes regiones de México. ${ }^{4}$

Escogimos el enfoque histórico estructural, que da cuenta de las posibles mediaciones que pueden influenciar al producto comunicativo: económicas, políticas, ideológicas, tecnológicas, culturales. Este enfoque, aunque puesto de moda en los años setenta, continúa vigente para el estudio de los medios de comunicación de una manera compleja, a fin de evitar la mera descripción de los procesos comunicativos.

El análisis histórico estructural, tal como ha sido desarrollado por los científicos sociales latinoamericanos, es una forma de aproximación dialéctica al estudio de la sociedad. Ésta caracteriza metodológicamente a toda una tradición de investigación, que tuvo su gran momento en los años setenta, pero que, pese a las grandes crisis mundiales, nosotros creemos que en la medida en que se han dejado atrás rigideces ideológicas y purezas epistemológicas insostenibles, es todavía una fuente rica para la generación de preguntas, hipótesis o intentos de respuestas y eventualmente incluso guías potenciales para la acción social (Sánchez Ruiz 1992).

\footnotetext{
${ }^{3}$ El caso de Puebla ha sido profusamente estudiado por José Toribio Medina, en particular la época colonial.

${ }^{4}$ Mientras que Veracruz está situado en el sureste de México, Oaxaca se encuentra en la costa sur del Pacífico. Más al norte, en la región centro-occidente, se encuentran Michoacán y Jalisco, en tanto que Yucatán está situado en la península del mismo nombre, al extremo sureste.
} 
Seguimos el método propuesto por Enrique Sánchez Ruiz para ese enfoque. Sin embargo, no abarcaremos la totalidad de estas mediaciones por exceder el objetivo del presente artículo.

\section{PRIMERO LO PRIMERO Y VUELTA AL CENTRO}

La primera imprenta de las Indias Occidentales se estableció en la capital de la Nueva España en 1535. Esteban Martín tuvo el privilegio de ser el primer impresor de América y la primera obra impresa en este continente lleva el nombre de Escala espiritual para llegar al cielo, de San Juan Clímaco. ${ }^{5}$ Cuatro años más tarde, el impresor lombardo Juan Pablos, llegó a México a fin de establecer un taller de imprenta a nombre de Juan Cromberger. Con el sello de este último, Juan Pablos sacó a la luz los impresos de la Nueva España gracias a un privilegio otorgado por Carlos V. Desde el establecimiento de esta imprenta, hasta finales del siglo XVI, se conocen 174 obras, además de otras 58 sin fecha. Ya desde 1541 tenemos noticia de la publicación de una hoja impresa: $R e$ lación del terremoto de Guatemala, antecedente del periodismo en México. Sin embargo, el que puede ser considerado como el primer periódico americano, lleva el nombre de Gaceta de México y Noticias de la Nueva España, aparecido en 1722 y redactado por Juan de Castorena y Urzúa. ${ }^{6}$

Al siguiente siglo del establecimiento de la imprenta en México y en Lima, se introdujo ésta a Puebla de los Ángeles en $1640 .{ }^{7}$ La producción de esta imprenta entre 1642 y 1821 fue de 2,700 documentos. Sin embargo, no contó con un periódico sino hasta

${ }^{5}$ No fue sino hasta 1584 cuando se estableció la imprenta en Lima. Cf. José Torre Revello 1991: 139.

${ }^{6}$ El segundo lugar de América donde se publicaron periódicos, fue Guatemala: en 1729 apareció la Gazeta de Goathemala. En 1743 apareció el primer periódico peruano: La Gazeta de Lima. La Habana ocupa el cuarto lugar cronológico entre las ciudades de América donde surgió el periodismo. La Gazeta de La Habana apareció en 1764.

${ }^{7}$ En 1641 llegaría esta maquinaria a Guatemala, aunque sólo hasta 1660 de forma definitiva. Mientras que en las provincias de Buenos Aires, los jesuitas comenzaron a imprimir de manera irregular desde 1700. Ibid: 148. 
1820. Se trata de El Tejedor y su compadre, de junio de 1820 , seguido ese mismo año por El Redactor poblano, El Católico, La Carreta y La Abeja Poblana. ${ }^{8}$

\section{"RELOJES FUNCIONANDO AL MISMO TIEMPO, PERO EN HORAS DISTINTAS" \\ La mediación tecnológica}

Si se intenta un recorrido que forzosamente tendría que ser a vuelo de pájaro por los establecimientos de la imprenta en cinco regiones de México, encontraremos diferencias fundamentales en los procesos.

La primera, y tal vez la más evidente, es la diferencia cronológica en el establecimiento de los talleres tipográficos.

El lugar a donde llegó la imprenta después de México y Puebla, fue Oaxaca, tomando en cuenta los nuevos descubrimientos, que sitúan el primer taller de imprenta en la vieja Antequera en 1687. Fue un particular, Diego Fernández de León, quien la transportó desde Puebla, siendo esta maquinaria la misma traída al nuevo mundo por Juan Pablos. Estaba a su cargo Antonio Díaz Maceda. De este taller de imprenta no se conoce más que un solo documento. Sin embargo, descubrimientos más recientes han incorporado una serie de títulos a la lista de impresos coloniales oaxaqueños. Ellos son: un billete de lotería para la conclusión del Oratorio de San Felipe Neri, de 1789; un Sermón pronunciado por Fray José Mariano Montúfar en 1734; un Sermón pronunciado por Juan Manuel Agüero en la Catedral en 1749 y un Sermón pronunciado por Fray Jesús María en 1773. No obstante, no se conoce la imprenta donde fueron sacados a la luz ni si es la de doña Francisca Flores, dueña del taller tipográfico a partir de 1720. También se encontró un folleto impreso en Zimatlán en 1789. Se trata de las Reglas, instrucción y gobierno de la Santa Iglesia Catedral de Antequera Valle de Oaxaca ajustadas al Concilio

${ }_{8}^{8}$ Para un análisis de estos periódicos, véase Coudart 2001. 
Mexicano a su erección y a la costumbre que siempre ha observa$d o$. Éste es un caso sumamente extraño, ya que actualmente en esa población sólo existe una imprenta nueva y no hay en su archivo ninguna prueba de la existencia de la imprenta colonial. ${ }^{9}$

Se sabe de otros documentos impresos en Oaxaca en 1811; uno de ellos es la proclama del obispo de Antequera a sus diocesanos, instándolos a unirse bajo las banderas realistas, en agosto de 1811.

Fue el presbítero José María Idiáquez, quien tuvo a su cargo la imprenta desde ese año y quien se encargó de fundir los tipos para la publicación de documentos. Este sacerdote era bachiller en teología y pertenecía a la orden de los filipenses. Se tienen noticias de que ese taller seguía funcionando todavía en 1828. Otros de los primeros talleres de imprenta que funcionaron en Oaxaca fueron el del gobierno, a cargo de Lorenzo Aldeco desde 1823, y la del Instituto de Artes y Ciencias de Oaxaca, en $1827 .{ }^{10}$

Estos nuevos descubrimientos nos llevan a articular un proceso más factible, ya que sólo tomó 47 años llevar la imprenta de Puebla hasta Oaxaca, considerando que el uso que se le dio en la vieja Antequera en un principio distó de ser exhaustivo.

Por otro lado, aparentemente el centralismo operaba en esta región, como para que no cupiera duda alguna en cuanto a establecer la imprenta en la ciudad de Oaxaca. Aunque ya se mencionó el documento impreso en la Villa de Zimatlán, no hay evidencia que pruebe que en efecto el taller de imprenta se encontraba en aquella población.

Le sigue en temporalidad, la instalación de la imprenta en Jalisco (Nueva Galicia en ese momento) a fines de 1792. Debido a la enorme centralización que siempre ha operado en el estado, hablar de los inicios de la prensa en Jalisco es, en verdad, hablar de los inicios de la prensa en Guadalajara.

A esta ciudad llegó la imprenta, con Mariano Valdés Téllez Girón a fine de 1792, quien obtuvo el privilegio solicitado al rey

\footnotetext{
${ }^{9}$ Cf. María Isabel Grañén Porrúa 1999.

${ }^{10}$ Cf. Sánchez Silva 1999.
} 
por diez años, durante los cuales ninguna otra persona podría imprimir sin su autorización.

Estableció su taller frente a la Plaza de Santo Domingo, en la finca que hasta hoy se conoce como la Casa de los Perros. La maquinaria del taller se trasladó desde Madrid, y a mediados de 1794 llegaron de la ciudad de México José Simón de la Rea, ilustre grabador, un encuadernador y un abridor de láminas y sellos a fin de dar al taller mayor lustre.

No se conoce la fecha exacta del establecimiento de la imprenta, pero se toma como base la impresión de las exequias de Fray Antonio Alcalde, celebradas en noviembre de 1792 e impresas ya en Guadalajara a principios de 1793, en vez de ser enviadas, según la costumbre, a la ciudad de México. Éste es, así, el primer documento salido de la imprenta de Valdés, aunque también se disputa la primacía una invitación a un acto de graduación del Seminario Conciliar.

Durante el año de 1793, se imprimieron otros documentos en este primer taller: una Novena a la Virgen de Aranzazu, Novena a la Virgen de Santa Ana, Actas del Capítulo Provincial Franciscano, Edicto del comisario General de la Santa Cruzada, Sumario de Indulgencias concedidas por la Santa Sede Apostólica a la Cofradía de San Felipe Neri, y Novena a la Virgen de Zapopan.

La producción total de este primer taller fue de alrededor de 100 títulos de diversos géneros, prevaleciendo aquéllos sobre cuestiones religiosas. Se sabe, además, que como era la costumbre de la época, en Guadalajara el taller de Valdés inauguró el uso de expender en las oficinas de la imprenta "las gacetas, así políticas como de literatura, recibiendo las suscripciones que quieran hacerse a ambas. Igualmente en dicha oficina se expenden cartillas, catones, variedad de libros y muchos devocionarios".

En 1807, el emprendedor caballero Valdés Téllez Girón, víctima de la epilepsia, tuvo que regresar a México. Al año siguiente, pasó la imprenta a manos de José Fructo Romero, quien la mantuvo hasta su muerte, acaecida en 1820. Bajo la dirección de este impresor nacido en Torrecampo de Castilla, salieron a la luz 
opúsculos y libros, así como los primeros periódicos de Guadalajara. En este taller se sacaron a la luz, hacia 1808, proclamas firmadas por el presidente de la Real Audiencia o por algunas otras autoridades, siendo sus productos más solicitados las novenas, las relaciones de méritos de diversos ciudadanos y encargos de otros lugares, como por ejemplo: Número de individuos atacados por la viruela en la ciudad de Durango (1798) o bien el Compendio Histórico de la fundación de Cartago en Nueva Granada (1803).

Nunca se albergó ninguna duda respecto al lugar donde la imprenta debía establecerse: Guadalajara era el centro de la actividad comercial y social del occidente; ninguna otra población de la zona llegaría a tener una importancia relevante desde el punto de vista de publicaciones, hasta casi finales del siglo XIX. Existía San Juan de los Lagos con su enorme feria comercial, sin embargo la actividad de la población se reducía a unas pocas semanas al año. Por otro lado, Lagos de Moreno, cuna de cierta actividad intelectual, estaba más aislada de los corredores comerciales del periodo y no sería sino eventualmente que se sacarían a la luz algunos impresos en dicha población.

El segundo taller de imprenta de Guadalajara fue el de Mariano Rodríguez, que empezó a funcionar con parte de la maquinaria de la imprenta de Fructo Romero en 1821. En esta imprenta salieron a la luz más de 89 impresos entre 1821 y 1824. Este taller siguió funcionando con distintos nombres hasta 1936.

En el mismo año de 1821 se fundó el tercer taller de imprenta, bajo la mano de Urbano San Román, quien lo puso a disposición del gobierno de Jalisco. De esas prensas saldría la mayor parte de la producción de periódicos y opúsculos federalistas. ${ }^{11}$

La llegada de la imprenta al primer puerto del país, Veracruz, data de la última década del siglo XVIII. No hay, sin embargo, una fecha precisa así como tampoco un personaje concreto a quien atribuir tal beneficio. José Toribio Medina apunta como primer documento veracruzano unas Alabanzas a San José, impresas en 1794.

${ }^{11} C f$. Del Palacio 2001. 
El Consulado ejerció un papel muy importante en el establecimiento de la primera imprenta e influyó sin duda en el carácter de los primeros impresos del estado. De hecho, Manuel López Bueno fue el impresor oficial del Consulado, antes de convertirse en el primer periodista veracruzano.

Fue López Bueno grabador, pintor y periodista nacido en 1761 en Veracruz, aunque de padre español. ${ }^{12}$ Trabajó durante diez años en los Reales Almacenes de Veracruz, escalando en la jerarquía, desde meritorio hasta oficial mayor interventor, y renunció por no ser ascendido a guardalmacén. Posteriormente fue nombrado cabo principal de 117 hombres para el plan de defensa en la guerra contra Inglaterra. En 1791, según sus propias palabras:

Establecí [...] una imprenta con las correspondientes licencias, sin faltarme el conocimiento de la poca utilidad que habría de proporcionar, por ser ésta una plaza enteramente mercantil y carecer de los auxilios de aulas, colegios, universidades y otros claustros que producen los sabios escritores y literatos cuyas continuas tareas deben el sudor de las prensas. ${ }^{13}$

Este taller se encontraba en la calle de las Damas y, gracias a él, introdujo "el uso de varios documentos impresos relativos a su consumo, que hasta la fecha eran desconocidos", tratándose éstos probablemente de machotes para libranzas o balanzas comerciales. Intervino en la política local, pretendiendo un puesto en el Ayuntamiento. Participó en la defensa de Veracruz contra los españoles y franceses. Continuó en Veracruz su actividad hasta 1812. Esta fecha coincide con su instancia para anular las elecciones capitulares, por lo que puede sospecharse que tuvo que salir de Veracruz debido a causas políticas.

${ }^{12}$ Aunque la Enciclopedia de México dice que nació en España y que llegó a Veracruz en 1794, adquiriendo el título de impresor del Consulado el año siguiente. Aquí nos basaremos en los datos brindados por Verónica Zárate en su artículo "Los albores del periodismo veracruzano. El Jornal Económico Mercantil como fuente histórica", 1995. Los datos en que ella se basa están tomados del memorial presentado por el mismo López Bueno al Rey Carlos IV, existente en el Archivo General de Indias.

${ }^{13}$ Memorial ya citado, en Verónica Zárate 1995. 
No es de extrañar, pues, que los primeros impresos hayan sido costeados por el Consulado. Esta inquietud comercial se manifestó en los primeros impresos: aparte de las Alabanzas al Señor San José, primer impreso veracruzano de 1794, se publicaron en Veracruz en 1795 la Real Cédula de erección del Consulado, el Almanak Mercantil o Guía de Comerciantes para el año de 179,6 y los primeros periódicos: El Correo de 1804, y sobre todo el Jornal Económico Mercantil, de 1806, y el Diario Mercantil de Veracruz, de 1807.

Se ha remarcado la importancia del puerto de Veracruz como principal receptor y trasmisor de noticias. Sin embargo, uno de los principales factores para establecer una imprenta en Veracruz fue la importancia del comercio y la necesidad de crear órganos de difusión y especialización del mismo. Los primeros impresos veracruzanos giraban mayormente en torno a los negocios que ahí se realizaban, a diferencia de otras ciudades como Guadalajara, donde éstos eran de carácter religioso. Ciertamente tienen el privilegio de iniciar la historia de la imprenta en Veracruz las Alabanzas a San José citadas más arriba; sin embargo, junto con una Novena a San Efrén, de 1802, un Septenario en culto y alabanza de la preciosísima sangre de Nuestro señor Jesucristo de 1815, una Novena en honor y alabanza del Santo Cristo del Buen Viaje del mismo año, y una Oración fúnebre para Maria de Braganza de 1819, son los únicos impresos religiosos que se conservan de esta primera etapa. Por otro lado, los destinados al comercio y a los asuntos públicos, entre 1795 y 1821 pasan de 35, incluyendo tres periódicos dedicados al primero de estos temas. No se conocen muchos impresos veracruzanos del periodo, ya que la destrucción de estos materiales fue masiva, tanto por las invasiones que sufrió el estado como por el clima poco propicio para la conservación de este tipo de documentos y el descuido de las autoridades al respecto.

Entre los materiales que se conservan en la Colección Lafragua de la Biblioteca Nacional, se encuentran unos pocos de Veracruz: Proclama de una Veracruzana y Viva Fernando VII, 
vivan nuestros amados reyes católicos y la valerosa nación espanola. Otro de estos papeles es un poema firmado por José María Villaseñor y Cervantes, secretario de la Intendencia del ejército de Xalapa, para celebrar el triunfo sobre el movimiento independentista llevado a cabo en esa ciudad, impreso sin embargo en México, al igual que otros dos, con algunas referencias a Veracruz, fechados en 1810, en contra de la Independencia. La Imprenta de Priani puede haber sido la segunda establecida en el puerto, aunque tampoco podría afirmarse que no se trate de la misma imprenta de Manuel López Bueno, cuyo nombre desde 1812 ya no figura en los impresos veracruzanos. Entre 1812 y 1820, los impresos sólo rezan "Impreso en Veracruz". De hecho, la imprenta de Priani y Quintana comienza a figurar en los impresos veracruzanos desde 1820 con diversos nombres: Imprenta del Gobierno Imperial Mexicano de Priani y Socio, Priani y Quintana, y Constitucional.

En dicho taller se imprimieron los papeles oficiales, sobre todo los relativos al imperio desde 1821, como asegura su primer nombre, aunque no sólo éstos, sino que también se imprimió en sus talleres el Plan de Veracruz para derrocar a Iturbide en 1822. Con el nombre de Imprenta Constitucional, dio a la luz dos Juguetillos en torno a la invasión de los piratas y la Historia del Primer Monarca del Reino Tulteco, ambos de 1821. Sin embargo, todos los nombres anteriores para denominar al taller de imprenta se utilizaron en diferentes fechas. No se encontraron documentos posteriores a 1822 impresos en este taller en el puerto, por lo cual se sospecha que Priani se mudó a Xalapa para operar la Imprenta del Gobierno, ya que su nombre figura en los periódicos Diario de Leyes y Decretos y El oriente, ambos publicados en aquella ciudad en 1824.

En Xalapa, ciudad de tránsito que adquirió otro estatus a raíz del establecimiento de la feria comercial, la fecha de establecimiento de la prensa es oscura: se dice que un periódico circuló ahí desde 1805, aunque nada se conoce de él; se trata de La Gazeta. De cierto se sabe que en 1824 ya existía ahí una imprenta estable- 
cida por el gobierno, en la cual se imprimieron desde ese año el Diario de Leyes y Decretos y El Oriente, cotidiano también, editado por el moderado Sebastián Camacho.

Ya existía una imprenta en Orizaba en 1799, perteneciente al convento de San José de Gracia, que sólo sirvió para imprimir las obras del servicio eclesiástico. A pesar de ser desde el siglo XVIII la población más culta de Veracruz y sede del único colegio existente durante las primeras décadas del siglo XIX, la primera imprenta particular se estableció ahí hasta 1839, curiosamente, sólo dos años después de establecida la primera fábrica textil, que cambiaría la fisonomía de la región, lo que hace pensar en la necesidad de una imprenta como negocio y como resultado de un progreso económico, más que como elemento fundamental para la enseñanza.

El establecimiento de la imprenta en otras ciudades del estado fue posterior. ${ }^{14}$

Este desarrollo de la imprenta se debió a la tendencia de regionalización particular de Veracruz, que obedece a la peculiar geografía de aquel estado, a la cual hay que aunarle la dificultad en los transportes y la escasez de carreteras que comunicaran a todo el territorio; el estado sufrió una fragmentación importante, lo cual dio lugar a regiones autónomas con necesidades económicas propias, manifestaciones culturales particulares y también periodísticas.

En el caso de Mérida, la capital de Yucatán, la imprenta fue llevada por Francisco Bates, "uno de los más ardientes liberales yucatecos", arribando de Europa a aquel lugar en 1813. Ese mismo año comenzó a publicarse el primer periódico yucateco: $E l$ Aristarco Universal, de Lorenzo de Zavala. El taller cambió de manos varias veces entre 1813 y 1821 , lo cual se ha prestado a

${ }^{14}$ Córdoba, en 1852, mientras que en Huatusco fue en 1847, a raíz del establecimiento del gobierno estatal en esa población en ese año y el siguiente. A Coatepec, la imprenta llegó en 1851, y finalmente a Ozuluama en 1862. En la década de los ochenta había imprentas en Tuxpan, Tlacotalpan y Coscomatepec. Periódicos de Atzálan se imprimían fuera del estado, en Teziutlán, por ser la población importante más cercana. Durante un tiempo, el periódico 2 de abril, que circulaba en Orizaba, se imprimió en Puebla. Cf. Del Palacio 1999. 
especular que podían haber existido cinco talleres de imprenta simultáneamente. ${ }^{15}$ La imprenta se utilizó en Mérida para dar a la luz, además de este periódico, que siguió publicándose hasta 1821, opúsculos diversos, proclamas y otros papeles oficiales: Proclama de los diputados de Cortes por la Provincia de Yucatán a sus habitantes (1813), Cuenta de gastos de la junta provincial de Censura (1814), Acuerdos del Ayuntamiento del Pueblo de Becal (1814); escritos patrióticos o en defensa de la Constitución: Clamores de la fidelidad americana contra la opresión (1814), Manifiesto de las notorias infracciones con que los señores capitanes generales de las provincias de la Nueva España y Península de Yucatán D. Félix María Calleja y D. Manuel Artazo insultan descaradamente a la Constitución (1813); Oraciones fúnebres y otros escritos religiosos: Oración fúnebre que dijo el 2 de mayo en la parroquia de Campeche el cura interino José Mariano de Cícero (1814), Novena de la Bienaventurada Santa María Magdalena (1817), Letanías del Santo nombre de Jesús (1818), Elogio Fúnebre para Doña Francisca de Braganza, celebrado en la Catedral de Mérida (1819), así como escritos del territorio de Tabasco, contiguo a la provincia de Yucatán: Actas del ilustre Ayuntamiento de Tabasco (1815). Como puede verse, la producción de este primer taller de imprenta fue muy variada y parecería no sesgarse hacia ninguna tendencia en especial.

Por último, el caso de Michoacán es muy distinto: un motor fundamental de la publicación de impresos en maquinaria portátil fue la guerra de Independencia. Y puede decirse que si se publicaron ahí algunos periódicos y opúsculos, fue sólo porque los insurgentes se encontraban casualmente en esa intendencia. No se puede hablar de una imprenta en Michoacán sino hasta 1827, cuando fue instalada y luego concesionada por el gobierno a Luis Arango.

Sin embargo, al parecer la primera iniciativa para establecer formalmente una imprenta en Michoacán fue de Rafael Núñez Moctezuma, impresor trashumante que gestionó la autorización

${ }^{15}$ Para el año 1814, funcionaba como Imprenta del Gobierno a cargo de Manuel Anguas; en 1815, bajo el nombre de Andrés Martín Martín y, finalmente, en 1820 como Imprenta de Domingo Cantón. Cf. Medina 1991. 
respectiva en agosto de 1820 . Así, dirigió una petición al propio virrey Conde del Venadito, expresándole que se encontraba deseoso de contribuir al bien público y disponía de una imprenta que podía surtir para que sirviera lo mejor posible. También tornó la solicitud al jefe político de Valladolid, Manuel Merino, quien la recibió con beneplácito pues ninguna imprenta se había establecido formalmente ni en esa población ni en ninguna otra parte de la intendencia. La iniciativa quedaría suspendida de momento debido a las circunstancias políticas prevalecientes.

Otra imprenta en la misma intendencia sería la que el capitán José Mariano Magán condujo a la villa de Zitácuaro; ya en Huaniqueo, en el Bajío de la misma intendencia, la milicia de Agustín de Iturbide lanzaría una proclama a los habitantes de Valladolid, el 12 de mayo de 1821. Las propias fuerzas iturbidistas, al merodear la capital de la intendencia, editaron desde la Hacienda de la Soledad y el Convento de San Diego, periféricos a Valladolid, hojas volantes y manifiestos. Traían una imprenta portátil dirigida por Rafael Escandón y Rafael Núñez, a la que se conocía como Imprenta del Ejército de las Tres Garantías, que se estableció en Valladolid. En ella se editó la capitulación de la ciudad.

Ramón de Huarte, cuñado de Iturbide, intendente y jefe político superior en Michoacán, le encomendó a Luis Arango (anteriormente comisionado para acompañar al ejército de Morelos como ayudante de la imprenta en Oaxaca), el montaje y dirección del pequeño taller oficial, que fue el primero que funcionó en Valladolid, el 23 de junio de 1821, en la calle del Obispado número 3. Por unos años sería el único taller en la capital del estado y serviría para reimprimir las comunicaciones de las autoridades civiles.

En septiembre de 1825, el Congreso expresó al gobernador que el estado tenía necesidad de una mejor imprenta y le pedían que se comprara. Se comisionó al propio Luis Arango para trasladarse a Veracruz a fin de realizar la transacción y el transporte de la maquinaria. La compra de la misma costó 3,059 pesos y tardó casi un año y medio para llegar a Valladolid. Se instaló en el Pala- 
cio de Gobierno y se procedió a dotarla de más herramientas de trabajo. Posteriormente, se ofreció en arrendamiento o en contrata, para que los michoacanos pudieran hacer uso más libre de ella. El primer concesionario fue el mismo Luis Arango, quien años más tarde, en 1828, estableció su propio taller. El segundo regente por contrata fue José Miguel de Oñate y, poco tiempo después, Juan Evaristo de Oñate. A partir del establecimiento formal de la imprenta en Michoacán, surgirían otros talleres donde se formarían impresores que encararían los retos del oficio en el estado.

Con el establecimiento formal de la imprenta en Michoacán floreció una actividad tipográfica de calidad. Entre los primeros impresos que se editaron se encuentran novenas, devocionarios, cartas pastorales, circulares y memorias del gobierno, algunos libros y, por supuesto, periódicos, de los que hablaremos en el siguiente apartado.

Se habla de haber pensado en una "utilidad común" como el fin último del establecimiento de la imprenta en Valladolid. De hecho, fue el gobierno y no un particular, quien compraría la maquinaria y la trasladaría a Michoacán desde Veracruz, sólo para ponerla al servicio de la gente por medio de una concesión. Tampoco en este caso hubo ninguna duda de que el taller debía establecerse en la capital del ya estado, instalándose incluso en el mismo Palacio de Gobierno.

\section{VINCULACIÓN DE LA IMPRENTA CON LAS INSTITUCIONES La mediación política y económica}

Vemos pues que la imprenta estuvo ligada a diferentes instituciones en los distintos lugares revisados, lo cual puede darnos la pauta de las posibles influencias de estas instituciones en los contenidos y en la orientación de los impresos.

En Guadalajara, la imprenta estuvo ligada a la Universidad y al Consulado, aunque mantuvo un carácter más independiente; ahora bien, lo importante es analizar quiénes formaban parte de estas dos instituciones. Existen estudios sobre la poderosa oligar- 
quía autonomista de Guadalajara, formada por apretadas redes de comerciantes y clérigos, cuya influencia alcanzaba tanto al Consulado como a la Universidad y a otras instituciones. ${ }^{16}$

En Veracruz, la influencia del Consulado sobre lo que se imprimía era decisiva y casi absoluta; en Michoacán, nacería prácticamente en el seno del gobierno estatal, aunque se daría la concesión a un particular, mientras que en Yucatán, su origen privado se extinguió prácticamente el año siguiente de su arribo a la provincia. Sólo en Oaxaca la imprenta parece haber gozado de independencia respecto de las principales instituciones. La primera imprenta parece haber servido a las necesidades del clero y no resultó de utilidad económica. Posteriormente, fue el padre Idáquez, un particular, quien puso a funcionar la maquinaria que habría de servir para publicar los periódicos independentistas. No fue sino hasta después de consumada la Independencia que la imprenta más importante estaría en manos del gobierno del nuevo estado.

Estos vínculos determinarían sin duda los tipos de materiales que se producirían en estos talleres. En la imprenta de Guadalajara se imprimirían novenas, elogios fúnebres, oraciones y cartillas y catones, mercancías de fácil venta en una ciudad muy religiosa y con un público lector formado por los estudiantes de la Universidad y de los colegios y el Seminario y, por otro lado, documentos oficiales para el servicio del gobierno y del Consulado. Los fines del establecimiento de la imprenta en este lugar fueron netamente comerciales. Don Mariano Valdés calculó pingües ganancias de la producción de una imprenta en la segunda ciudad más grande del virreinato, que contaba con un Consulado y pronto establecería su universidad, además de contar con diversos colegios y el Seminario. Guadalajara había probado poseer una oligarquía poderosa con sed de autonomía. Valdés habría de constatar que el taller de imprenta sería un negocio provechoso por la venta de material escolar, novenas y oraciones, además de los diversos documentos oficiales y comerciales.

$\overline{{ }^{16} \text { Cf. Olveda } 1991 .}$ 
En la imprenta de Valladolid, las mercancías culturales no serían muy distintas, ya que Luis Arango buscaría obtener provecho de su concesión en una ciudad que seguía consumiendo oraciones y novenas, con un gobierno que requería publicar edictos y ordenanzas diversas.

La imprenta de Veracruz dio a la luz, en primera instancia, los documentos emitidos por el Consulado, los cuales podían ser de interés sobre todo para los comerciantes, no sólo del Puerto, sino de todo México, como es el caso del Jornal Económico Mercantil, el cual tenía una circulación enorme, desusada para su época. A pesar de que aparentemente López Bueno no buscaba la ganancia económica, según lo declaró, sabiendo que en el lugar donde establecía la imprenta carecía de las instituciones educativas que tradicionalmente eran el mercado de los impresos, su relación con el Consulado resultó ser de gran utilidad.

La primera imprenta de Oaxaca no obtuvo ganancias por la impresión del Sermón fúnebre. Posteriormente la imprenta de Idáquez, tal vez por su carácter independiente, dio a luz tanto los periódicos independentistas como las proclamas del obispo a favor de la causa realista, además de oraciones diversas y otros impresos, como billetes de lotería. La Imprenta del Gobierno dio a luz las primeras recopilaciones de leyes y las discusiones del Congreso, además de otras noticias relevantes para la población y para los periódicos políticos de la segunda década del siglo XIX.

La imprenta de Yucatán tendría utilidades diversas: de inmediato se destinó a la publicación del periódico de Lorenzo de Zavala, así como otros papeles públicos; por otro lado, sirvió a los fines del gobierno al reproducir diversas órdenes y proclamas, reduciendo así los costos y, finalmente, también se utilizó para imprimir otro tipo de proclamas patrióticas y periódicos en contra del gobierno provincial, aunque también imprimiría oraciones diversas.

Debemos recordar que la imprenta era, antes que nada, un negocio. Muchas veces en los estudios sobre prensa se tiende a olvidar la parte meramente comercial de este instrumento. En efec- 
to, sería parte esencial del esclarecimiento de las conciencias y un instrumento fundamental para la apertura de la esfera pública pero, antes que nada, era un negocio, y sus dueños tendían a imprimir aquellos productos que les redituarían ganancia.

\section{LOS INICIOS DEL PERIODISMO EN LAS REGIONES El producto comunicativo}

En cuanto a los inicios del periodismo en las cinco regiones, también encontramos diferencias fundamentales.

El primer periódico impreso fuera de la ciudad de México fue la Gaceta del real tribunal del Consulado de Veracruz en 1795. El Almanaque o Almanak Mercantil del año siguiente no puede considerarse un periódico, sino una "guía de comerciantes para el año de 1796". Estas dos publicaciones fueron financiadas en su totalidad por el Consulado e impresas por Manuel López Bueno; sin embargo, el Correo Mercantil de 1804 era ya propiedad del impresor, quien dos años después le cambió el nombre por el de Jornal Económico Mercantil de Veracruz.

Este periódico fue uno de los más influyentes de su tiempo, no sólo imponiendo un modelo de lo que un papel público debía incluir —el cual fue seguido fielmente por los periódicos del puerto de Veracruz hasta el siglo xx-, sino por su alcance geográfico y utilidad real fuera del estado. En la Imprenta de Priani, se darían a la luz el Diario Político y Mercantil de Veracruz en 1821 y su posible sucesor de 1822, el Diario de Veracruz, que circuló entre diciembre de ese año y febrero del inmediato siguiente. En sus páginas puede apreciarse cómo transcurría la vida del puerto en la difícil transición al sistema republicano, ya que se detallan los acontecimientos de la revolución.

El año de 1824 fue el de inicio del periodismo en Xalapa, ciudad de tierra adentro, famosa por su feria comercial. La necesidad de publicar periódicos en esa población obedeció al establecimiento del Congreso del Estado en 1824 y, por tanto, la publicación de los decretos y discusiones del mismo en un periódico 
especialmente dedicado a ese fin y, por otro lado, esto provocó la aceleración de la necesidad de discusión de los "asuntos de interés público", de lo cual nació El Oriente, de Sebastián Camacho.

Los primeros periódicos tapatíos que se publicaron en el taller de Fructo Romero fueron: El Correo Científico y Literario de Salamanca (1808) y el Semanario Patriótico (1809), ambos copia de los periódicos publicados en España. Después, el primer periódico insurgente El Despertador Americano (1810), así como sus contrapartes El Telégrafo de Guadalajara (1811) y El Mentor de la Nueva Galicia (1812), todos producto de la pluma de Francisco Severo Maldonado, también saldrían del taller de Romero. Posteriormente, ya fruto de los otros talleres de imprenta, se darían a la luz más de 40 periódicos de diferentes inclinaciones políticas, defendiendo el centralismo o el federalismo, en pro o en contra de la Iglesia, entre 1812 y $1835 .{ }^{17}$

Puede hablarse de la existencia del periodismo en Oaxaca, como se dijo más arriba, desde 1812, en el momento en que, por la necesidad de difundir las ideas de la guerra de Independencia, José María Morelos y Pavón y Carlos María de Bustamante utilizaron las habilidades del ya mencionado padre José María Idiáquez para editar en tierras oaxaqueñas los periódicos insurgentes $E l$ Ilustrador Americano, y El Semanario Patriótico Americano del mismo año, El Correo Americano del Sur y Sud, continuador del Despertador de Michoacán, ambos de 1813.

Ya en 1821 se publicó El Oaxaqueño Constitucional, el cual propugnaba la formación del país con base en una constitución. Del mismo carácter combativo son los periódicos aparecidos en la década de los veinte, defendiendo a centralistas o federalistas. Tal es el caso de Cartas al pueblo de 1827, El Oaxaqueño Libre de 1829, El Oaxaqueño Federalista, del mismo año y El Baluarte de la Ley y El Zapoteco, de 1833 . $^{18}$

El periodismo se inició inmediatamente después de establecida la imprenta en la provincia de Yucatán, como ya se dijo. Ade-

${ }^{17}$ Cf. Del Palacio 2001.

${ }^{18}$ Cf. José Toribio Medina. Facs. 1991, Francisco José Cervantes y Carlos Sánchez 1999 y Carlos Sánchez Silva 1999. 
más de El Aristarco, se publicaron en 1813 El Misceláneo y El Redactor Meridiano. Al año siguiente, aparecieron El Filósofo Meridiano y El Sabatino; posteriormente, en 1820, aparecieron El Hispanoamericano y Lealtad Yucateca. El año siguiente, circularon en tierras yucatecas Periódico Constitucional y El Yucateco.$^{19}$

Los antecedentes más directos de la prensa en Michoacán son las gacetas insurgentes impresas en prensas portátiles en los diversos lugares a donde llegaban los insurrectos. José María Cos, Andrés Quintana Roo e Ignacio López Rayón, redactores de El Ilustrador Americano, el cual se dio a conocer en Sultepec, hoy estado de México en 1812, se refugiarían en los límites de la intendencia de Valladolid, de Michoacán, y se establecieron en Tlalpujahua el 12 de octubre de 1812. Allí continuaron con su labor, imprimiendo los últimos ejemplares de El Ilustrador Americano, cuyo principal objetivo era dar partes de guerra y difundir las hazañas militares de la insurgencia. El primer órgano periodístico del estado fue El Astro Moreliano, que salió a la luz pública el 2 de abril de 1829. El año siguiente surgieron El Michoacano Libre, El Tapabocas y La Banderilla. ${ }^{20}$

¿Qué se puede concluir con base en estas comparaciones de los productos comunicativos dados a la luz en las diferentes regiones?

En Veracruz, el periódico fue un vocero de los intereses comerciales del puerto, hasta 1824, cuando en Xalapa, una vez establecido ahí el gobierno del nuevo estado y publicada la Constitución, la prensa serviría para defender el nuevo orden.

En Michoacán, así como en Oaxaca, hubo periódicos insurgentes de vida efímera, mientras que los primeros periódicos ya formalmente establecidos tanto en la antigua Valladolid como en Oaxaca, fueron órganos de defensa de la causa federalista y de la Constitución de 1824.

\footnotetext{
${ }^{19}$ Idem.

${ }^{20}$ Cf. Pineda Soto 2003.
} 
En Yucatán, el primer periódico se publicó con el fin de ilustrar a las masas con las ideas liberales, principalmente aquéllas plasmadas en la Constitución de Cádiz de 1813.

En Guadalajara los primeros periódicos fueron copia de semanarios españoles, de donde los intelectuales tomarían las ideas de avanzada plasmadas en aquellos órganos por los liberales españoles como Manuel Quintana y, después, órganos que defendieron o atacaron a la Independencia. Una vez concluida ésta, la prensa serviría como vocero de los distintos grupos de poder en la entidad, a favor de las distintas formas de gobierno posibles para el nuevo país, así como tribuna de las ideas respecto al lugar que debería ocupar la Iglesia en una nación moderna.

Estas diferencias temáticas y de intereses, podrían ser atribuibles parcialmente a los desfases cronológicos en la aparición de los diversos órganos de prensa de las ciudades citadas; sin embargo, aparte de esa sola cuestión, podemos señalar que los periódicos de las distintas regiones estaban interesados en las discusiones generales de la forma de gobierno del nuevo país y, antes de 1821 en el caso de Jalisco y Yucatán, en la discusión de los principios constitucionales. Este tema parecería no tener mayor interés en Veracruz, Oaxaca y Michoacán, donde no existía una élite ilustrada fuerte y donde parecían ser otros los intereses del momento (el comercio en Veracruz, la lucha por la independencia en Michoacán y Oaxaca).

Creemos que es necesario seguir profundizando en las mediaciones que atraviesan al fenómeno periodístico en sus orígenes en México; sobre todo, fijar la mirada en las regiones, apartándola del centro, donde siempre ha estado, aunque no deje de ser ahí donde se forjó la esencia de la historia en un país centralista como México.

Mucho falta por averiguar para poder llevar a cabo un estudio comparativo de las regiones en materia periodística. Consideremos este trabajo como el inicio de una investigación más profunda que nos puede llevar a conocer y explicar mejor las diferencias y semejanzas en los procesos culturales de las regiones de México durante el siglo XIX. 


\section{REFERENCIAS BIBLIOGRÁFICAS}

Burke, Peter (1997) Historia y teoría social. México: Instituto de Investigaciones José María Luis Mora.

COUdART, Laurence (2001) "Nacimiento de la prensa poblana. Una cultura periodística en los albores de la independencia, 1820-1828”, en Miguel Ángel Castro (coord.), Tipos y caracteres: la prensa mexicana 1822-1855. México: UNAM.

Del Palacio, Celia (1999) Índice Hemerográfico Veracruzano. Xalapa: Universidad Veracruzana.

- (2001) La disputa por las conciencias. Los inicios de la prensa en Guadalajara, 1809-1835. Guadalajara: Universidad de Guadalajara.

Grañén Porrúa, Isabel (1999) "Los orígenes de la imprenta en Oaxaca", Historia de la imprenta en Oaxaca. Oaxaca: Biblioteca Francisco de Burgoa/oABJo.

GuErra, Francois Xavier (1992) Modernidad e independencias. México: Fondo de Cultura Económica.

Habermas, Jürgen (1991) The Structural Transformation of the public Sphere. Cambridge: MIT Press.

Medina, José Toribio (1991) La imprenta en Oaxaca, Guadalajara, Veracruz, Mérida y otros lugares, edición facsimilar. México: UNAM.

Olea, Héctor R. (1995) La imprenta y el periodismo en Sinaloa 1826-1950. Culiacán: UAS-DIFOCUR.

Olveda, Jaime (1991) La oligarquía de Guadalajara. México: Conaculta.

Pérez Herrero, Pedro (1991) Región e historia en México (1700-1850). México: Instituto Mora.

PInEda Soto, Adriana (2003) La historia de la prensa política en Michoacán en el siglo XIX, tesis doctoral. México: UNAM.

Ruız Cervantes, Francisco José, y Carlos Sánchez Silva (1999) "La imprenta y la prensa en Oaxaca, siglos XIX y xx", en Celia del Palacio M. (comp.), Historia de la prensa en Iberoamérica. Guadalajara: Altexto.

SÁnchez Ruiz, Enrique (1992) Medios de difusión y sociedad. Notas críticas y metodológicas. Guadalajara: Universidad de Guadalajara.

SÁnchez Silva, Carlos (1999) "La imprenta en Oaxaca, 1821-1876. De la especulación a la incertidumbre", Historia de la imprenta en Oaxaca. Oaxaca: Biblioteca Francisco de Burgoa-OABJo.

Torre Revello, José (1991) El libro, la imprenta y el periodismo en América durante la dominación española. México: UNAM.

ZÁrate, Verónica (1995) "Los albores del periodismo veracruzano: El Jornal Económico Mercantil de Veracruz como fuente histórica", Revista Secuencia, núm. 33, septiembre-diciembre. Veracruz: Instituto Mora. 